\title{
Transparência ativa em organizações governamentais de sustentabilidade ambiental
}

Active transparency in governmental organizations for environmental sustainability

Transparencia activa en las organizaciones gubernamentales de sostenibilidad ambiental

(9) Danilo Rothberg

- Professor do Departamento de Ciências Humanas da Faculdade de Arquitetura, Artes e Comunicação (Faac) da Universidade Estadual Paulista (Unesp)

- Coordenador do Programa de Pós-Graduação em Comunicação da Faac/Unesp

- $\quad$ Doutor em Sociologia, mestre e bacharel em Comunicação pela Unesp

- $\quad$ E-mail: danilo.rothberg@unesp.br 


\section{ANO 16 • NÚMERO 31 • 2 SEM. 2019 • ORGANICOM

\section{Resumo}

São pouco conhecidas as características dos diferentes patamares de desempenho da comunicação pública produzida por assessorias de organizações governamentais. Este texto busca contribuir para preencher tal lacuna, ao descrever e interpretar os resultados de um estudo empírico de análise de conteúdo, que conduzimos com o objetivo de caracterizar a qualidade da comunicação digital produzida pelas assessorias de organizações governamentais ambientais das 27 unidades federativas brasileiras. Os resultados indicam oportunidades de aperfeiçoamento da comunicação e sugerem uma associação positiva entre desenvolvimento humano e transparência ativa, a ser explorada por estudos futuros.

PALAVRAS-CHAVE: COMUNICAÇÃO PÚBLICA •TRANSPARÊNCIA ATIVA•SUSTENTABILIDADE AMBIENTAL.

\section{Abstract}

The characteristics of the different levels of performance of the public communications produced by governmental organizations offices are little known. This paper seeks to contribute to fill this gap by describing and interpreting the results of an empirical study of content analysis that we conducted with the objective of characterizing the quality of digital communication produced by the offices of environmental governmental organizations of the 27 Brazilians states. The results indicate opportunities to improve communication and suggest a positive association between human development and active transparency to be explored in future studies.

\section{KEYWORDS: PUBLIC COMMUNICATIONS・ACTIVE TRANSPARENCY・ENVIRONMENTAL SUSTAINABILITY.}

\section{Resumen}

Las características de los diferentes niveles de desempeño de la comunicación pública producida por asesores de organizaciones gubernamentales son poco conocidas. Este texto busca contribuir a llenar este vacío describiendo e interpretando los resultados de un estudio empírico de análisis de contenido, que realizamos con el objetivo de caracterizar la calidad de la comunicación digital que ha sido producida por las asesorías de las organizaciones gubernamentales ambientales en las 27 unidades federativas brasileñas. Los resultados indican oportunidades para mejorar la comunicación y sugieren una asociación positiva entre el desarrollo humano y la transparencia activa para ser explorada en futuros estudios. 


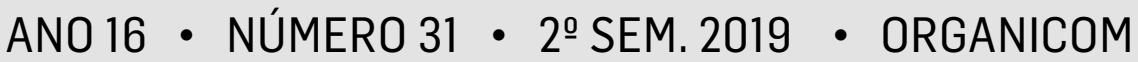

\section{INTRODUÇÃO}

A

s razões que podem explicar o desempenho da comunicação pública produzida por assessorias especializadas de governos democráticos para divulgar políticas públicas, em seus diversos aspectos, permanecem como um dos objetos que mais requer exploração científica na atualidade. Ao iluminar parcialmente casos empíricos isolados em relação a um número limitado de variáveis, específicas em função de determinadas localidades e culturas nacionais, a literatura acadêmica acessada por meio de periódicos de circulação internacional avança de modo a proporcionar indicações promissoras, mas de complexa aplicação global, contexto que deixa importantes questões em aberto.

Entre os aspectos verificados pelas pesquisas, que podem influenciar a performance dos assessores governamentais na publicização de informações sobre políticas públicas, estão as características da legislação de acesso a dados sobre programas públicos, as formas de contratação e regime de trabalho dos assessores, modelos e papéis profissionais, e condições de autonomia em relação ao governante de turno. Também há, ainda que mais raramente, estudos sobre a influência do ambiente econômico e social, que buscam correlações com aspectos como desempenho macroeconômico, estágio de consolidação democrática, existência de pluralismo midiático e liberdade de imprensa.

Tais aspectos são encontrados principalmente em estudos que têm países da Europa Ocidental e Estados Unidos como seu objeto. Na América Latina, em geral, e no Brasil, em particular, são escassas as abordagens preocupadas com a busca, com rigor e sistematicidade, de conhecimento sobre os diferentes níveis de performance dos assessores de comunicação pública produzida por governos democráticos para divulgar políticas públicas em suas diversas dimensões.

A própria determinação de critérios de aferição de desempenho da comunicação pública, inclusive, embora de especial complexidade, pode ser encontrada em estudos na literatura global, mas permanece como um tema praticamente ausente em países nos quais a redemocratização ocorrida após o fim dos regimes ditatoriais vigentes entre as décadas de 1960 e 1980 ainda requer, como é o caso brasileiro, o desenvolvimento de valores e condutas típicos do serviço público em democracias consolidadas. Diante da fragilidade das diretrizes para sua atuação profissional, os assessores de comunicação viram sua performance ser afetada pela intromissão de governantes ansiosos por fazer propaganda política, em afronta aos princípios constitucionais de impessoalidade no serviço público e proibição de promoção pessoal.

No Brasil, em particular, os assessores de comunicação pública assistiram à promulgação da lei de acesso a informações (12.527/2011) e ao decreto que a regulamenta (7.724/2012), com impactos sobre sua atuação ainda pouco estudados, 0 que sugere a permanência da escassez de referenciais para seu desempenho, a despeito do avanço, em muitos países, de padrões e práticas para o exercício de funções para o atendimento do direito à informação sobre ações, programas e políticas públicas. Em áreas de políticas públicas que sofreram mudanças devido ao surgimento de novas evidências científicas e acordos globais, como a sustentabilidade ambiental, a falta de orientações se revelou ainda mais crucial. Há espaço para pesquisas sobre a qualidade da atuação profissional no contexto da transparência ativa, critérios de desempenho e conhecimento de fatores associados às diferentes performances.

Este texto busca contribuir para preencher tal lacuna, ao descrever, comentar e interpretar os resultados de um estudo de análise de conteúdo que conduzimos nos anos de 2014 a 2017, com o objetivo de caracterizar a qualidade da comunicação digital produzida pelas assessorias dos governos das 27 unidades federativas brasileiras para divulgar políticas públicas 
de sustentabilidade ambiental'. 0 estudo incluiu dois conjuntos distintos de dados analisados. 0 primeiro foi composto por 284 páginas web das secretarias estaduais e Ministério do Meio Ambiente (Rothberg, 2018). 0 segundo, objeto deste texto, é composto por 607 páginas web de organizações governamentais ambientais ou equivalentes, de caráter predominantemente executivo, em sua maioria instituídas como autarquias, institutos, fundações de direito público ou empresas de economia mista controladas pelo Estado. Elas são responsáveis pela execução direta de um extenso rol de ações previstas pelas políticas estaduais de meio ambiente (em geral propostas pelo Poder Executivo e aprovadas pelo Poder Legislativo), incluindo desde a emissão de licenças, fiscalização, determinações de padrões, realização de estudos etc. até operações de saneamento básico e tratamento de água, passando por gestão florestal e de recursos hídricos.

Ambos os corpus foram submetidos a análise de conteúdo orientada por vinte categorias, elaboradas com base na literatura sobre avaliação de políticas públicas. Os resultados indicam oportunidades de aperfeiçoamento da comunicação das organizações governamentais no cenário das exigências legais de transparência ativa, em particular na abrangência e profundidade das informações.

E, enquanto os resultados da análise de 284 páginas web das secretarias estaduais e Ministério do Meio Ambiente sugeriram uma associação positiva entre desempenho econômico e social e qualidade da comunicação pública, a ser apurada em estudos futuros, conforme trabalho já publicado (Rothberg, 2018), o conjunto analisado de 607 páginas web de organizações governamentais ambientais sugere uma associação entre desenvolvimento humano e desempenho da comunicação, também dependente de verificação adicional. Neste sentido, move-se a busca pela caracterização dos diferentes patamares de performance dos comunicadores públicos em organizações governamentais, trazendo contribuições para descortinar programas de pesquisa.

No percurso deste texto, são desenvolvidas teorizações pertinentes; a metodologia de investigação é descrita; e os resultados centrais são apresentados e interpretados à luz da literatura pertinente. As considerações finais abrangem limites do desenho de pesquisa e indicações para estudos futuros.

\section{TEORIZAÇÕES PERTINENTES}

A atuação da comunicação pública digital produzida por assessores em secretarias de governo e organizações governamentais para divulgar, com rigor e sistematização, informações sobre políticas públicas e construir ou manter relações de mão dupla com cidadãos e setores sociais se dá no contexto do desenvolvimento, desde o surgimento da internet, dos diversos formatos de governo eletrônico e democracia digital (Dahlberg, 2011). 0 primeiro corresponde à oferta de uma miríade crescente de serviços, como pagamento de taxas, obtenção de licenças e certificações, registros etc. A segunda se refere à disponibilidade de meios de ampliação da participação nos processos de tomada de decisão pública, que assumem diferentes feições conforme o poder institucional de origem.

Ambos se encontram bastante intrincados, a ponto de o design de construção web buscar uma combinação singular entre eles a fim de fomentar uma experiência única de cidadania digital. 0 processo se desdobra tal como se o exercício de direitos políticos e sociais por meio de estruturas do setor público, com impacto sobre as várias esferas do cotidiano - da saúde ao orçamento participativo, da escola ao conselho municipal de educação, por exemplo - pudesse ou devesse equivaler

1 Agradecemos à Fundação de Amparo à Pesquisa do Estado de São Paulo (Fapesp) pelo auxílio concedido à pesquisa. As opiniões, hipóteses e conclusões ou recomendações expressas neste material são de responsabilidade do autor e não necessariamente refletem a visão da Fapesp. 
ao conforto de uma hoje rotineira operação comercial on-line de aquisição de produto ou serviço (Benjamin; Potts, 2018; Coleman; Blumler, 2009).

Trata-se, aparentemente, de uma lacuna para a qual, em certa perspectiva, as redes sociais trouxeram uma solução provisória, mas ao custo da imposição de sua lógica errática de postagens e comentários em reação às supostas e passageiras preferências dos usuários, em um fluxo à deriva (Rothberg, 2014). Neste contexto, outra escassez foi justamente aquela de conhecimento capaz de fundamentar uma trilha segura de aperfeiçoamento baseada nos conceitos da comunicação pública tal como ela passou a ser pensada no Brasil na redemocratização após 1985.

Entre os diversos significados de comunicação pública presentes nas pesquisas da área, que abrangem de propaganda oficial a radiodifusão, passando por redes sociais e portais web, destacam-se as iniciativas de secretarias de governo e organizações governamentais que disseminam informações relevantes aos diversos segmentos sociais para facilitar o acesso a serviços públicos, prestar contas sobre a atuação governamental e reconhecer o pertencimento à cidadania (Duarte, 2011; Miola; Marques, 2017).

O empoderamento da sociedade civil exige a entrada de outros atores na produção e circulação de comunicação de interesse público, como instâncias de participação política dos diversos agentes sociais na formulação da decisão pública. A comunicação pública passa a incluir, desta forma, tanto a dimensão governamental, centrada nos "fluxos de informações e padrões de relacionamento envolvendo o Executivo e a sociedade", quanto a dimensão política, que requer a "conquista de opinião pública em relação a ideais ou atividades que tenham relação com o poder", a fim de permitir a "viabilização do direito social individual e coletivo à informação, à expressão, ao diálogo e à participação" (Duarte, 2011, p.126).

A comunicação da instituição pública pode proporcionar o reconhecimento da cidadania ao se afirmar como "elemento estratégico da mediação entre os atores cívicos e o governo, visando criar e/ou reforçar o vínculo social entre os parceiros da ação pública", segundo Matos (2011, p.44); além disso, é necessária para estabelecer relações de proximidade e diálogo e contornar as limitações impostas pelas mídias comerciais, que dedicam um "lugar frágil" à vida cívica (Zémor, 2009, p.231).

A "construção da comunicação pública como debate público", segundo Weber (2017, p.27), requer o estabelecimento de práticas que devem estar situadas para além dos limites impostos por Estado e mercado. "As variáveis da comunicação nas democracias têm origem na informação e na participação, através de processos de visibilidade e acessibilidade que permitem saber, refletir, argumentar, se posicionar e deliberar", indica Weber (2017, p.28, grifo do autor), de forma que a "igualdade com respeito à diferença" se mostra essencial aos formatos e processos de realização de comunicação pública, se o predomínio do interesse público for buscado sistematicamente, inclusive para a responsabilização (accountability) de mandatários pelas políticas públicas que coordenam (Weber, 2017, p.33). 0 alinhamento da comunicação com o interesse público exige, neste contexto, a delimitação de estratégias adequadas, que impõe restrições ao atendimento de demandas circunstanciais motivadas pelo horizonte de curto prazo (Kunsch, 2018).

A concretização de princípios da comunicação de interesse público em políticas objetivas de comunicação, que contenham prescrições substantivas sobre o que e como divulgar, como e quando estabelecer o diálogo e recolher feedback, além de prestar contas sobre o devido aproveitamento do feedback, é um dos maiores desafios dos comunicadores em atuação em estruturas de governos democráticos em todo o planeta.

No Brasil, as diretrizes do governo federal detalham padrões gráficos e de navegação para as páginas web de seus diversos órgãos e setores (Brasil, 2014), mas as indicações de conteúdo limitam-se praticamente ao já disposto na própria legislação federal pertinente. Segundo o decreto 7.724/2012, que regulamenta a lei de acesso a informações (Brasil, 2011, 2012), 
em seu artigo $7^{0}$, nos formatos de transparência ativa na web "deverão ser divulgadas [...] informações sobre [...] programas, projetos, ações, obras e atividades, com indicação da unidade responsável, principais metas e resultados e, quando existentes, indicadores de resultado e impacto", incluindo "respostas a perguntas mais frequentes da sociedade".

Este requisito mínimo determinado pela legislação federal brasileira está aquém do estágio que muitos países já atingiram, como Estados Unidos, Reino Unido e Nova Zelândia, que definem uma lista detalhada de classes de informação necessárias à comunicação pública na web e exigem esquemas periódicos que determinam o escopo da publicação on-line de informação sobre ações e programas públicos, com os quais cada órgão de governo deve se comprometer (Darbishire, 2010; Dokeniya, 2013).

Darbishire (2010), em estudo do Banco Mundial, lista catorze classes, consideradas padrões ideais, abrangendo os seguintes aspectos de informação: institucional; organizacional; operacional; decisões e atos; serviços públicos de informação; orçamento; reuniões abertas; tomada de decisão e participação; subsídios; contratos; listas, registros, bancos de dados; dados armazenados; publicações; direito à informação.

Já a Organização dos Estados Americanos lista dezessete classes de informações de relevância permanente (OAS, 2012), incluindo planos estratégicos, códigos de governança e indicadores de desempenho, além de relatórios de auditoria.

Em termos gerais, na perspectiva democrática, a transparência deve "reforçar a competência cívica em toda a comunidade política e ajudar a 'reverter' as diferenças existentes na escala da informação" efetivamente disponível entre os diversos setores sociais, segundo Meijer, Hart e Worthy (2018, p.506). "Na perspectiva constitucional, as configurações da transparência devem fortalecer controles e balanços institucionais", e na perspectiva do aprendizado social, "a posição desejável é aquela em que os debates públicos são alimentados por 'feedback rico' - narrativas com muitas fontes e muitas perspectivas, relevantes e oportunas - sem sobrecarregar os cidadãos" (Meijer; Hart; Worthy, 2018, p.507).

\section{METODOLOGIA DE AVALIAÇÃO DA COMUNICAÇÃO PÚBLICA PARA SUSTENTABILIDADE}

Sob o desenho de nossa pesquisa, foi avaliada a presença de informações sobre políticas públicas de sustentabilidade ambiental provenientes de todas as 607 páginas web dos portais oficiais de organizações governamentais ambientais ou setores de governo equivalentes das 27 unidades federativas brasileiras disponíveis nos anos de 2016 e 2017, período selecionado por conveniência (lista com endereços disponível como Apêndice²). Neste censo de 607 unidades de análise, está incluído 0 conteúdo textual das páginas web, cada uma delas acessada por um endereço on-line distinto, sendo excluídos os conteúdos imagéticos e aqueles acessados por meio de links para páginas externas.

A análise de conteúdo foi realizada por meio de classificação em vinte categorias organizadas em seis eixos, metodologia utilizada em estudos anteriores (Rothberg, 2014, 2015, 2018). As categorias foram formuladas com base na literatura sobre avaliação de políticas públicas que contempla os diversos fatores implícitos na tomada de decisão pública e a normatividade da legislação federal de acesso à informação no Brasil (Brasil, 2011, 2012), além de aspectos da literatura internacional sobre o quê e como divulgar (Darbishire, 2010; Dokeniya, 2013; OAS, 2012).

2 Disponível em: https://tinyurl.com/y9f2ejeo. Acesso em: 24 jan. 2020. 
Além disso, a lista de categorias também responde a preocupações específicas advindas dos desafios globais da sustentabilidade ambiental e dos esforços de adaptação e mitigação dos efeitos da mudança climática pelo Acordo de Paris (ONU, 2015, 2017), um instrumento de cooperação transnacional gerido pela Organização das Nações Unidas. A contribuição proposta pelo Estado brasileiro depende fundamentalmente da ação de organismos locais e regionais, administrados por legislações estaduais e federal específicas.

As condições de validade, homogeneidade e exaustividade das categorias que formulamos foram verificadas e confirmadas em pré-testes, em linha com as prescrições da metodologia de análise de conteúdo (Fonseca Junior, 2006; Krippendorff, 1980).

As categorias de análise de informações sobre políticas públicas de sustentabilidade foram estas: Eixo 1: antecedentes e diagnósticos: 1. Condições sociais; 2. Condições econômicas; 3. Cenário político; 4. Estágio de desenvolvimento científico e tecnológico; 5. Informações legais. Eixo 2: propósitos: 6. Objetivos; 7. Metas; 8. Recursos e critérios de eficiência; 9. Ações; 10. Informações operacionais, parcerias e convênios para o acesso a benefícios.

Eixo 3: normas e padrões: 11. Prevenção de riscos; 12. Recursos de gestão. Eixo 4: públicos e setores beneficiados: 13. Públicoalvo; 14. Instrumentos de relacionamento. Eixo 5: Indicadores de impactos sociais: 15. Bem-estar; 16. Igualdade; 17. Satisfação do usuário. Eixo 6: Indicadores de impactos econômicos: 18. Eficácia; 19. Efetividade. 20. Custo-efetividade.

A coleta de dados ocorreu entre 2.1.2016 e 31.12.2017, e a informação disponível em cada uma das 607 páginas web/unidades de análise foi avaliada conforme uma escala de pontos, em relação à sua correspondência para cada uma das vinte categorias de análise de conteúdo, usando-se 1 para registrar a presença de qualquer informação correspondente em cada categoria, e 0 (zero) para registrar a ausência de informações correspondentes. Neste sentido, uma política pública apresentada com informações correspondentes ao total das vinte categorias receberia 20 pontos. 0 número de pontos efetivamente obtido na avaliação de informações sobre cada política, quando considerado em relação ao máximo de 20 pontos, gerou um número percentual, indicando a abrangência das informações sobre políticas de sustentabilidade veiculadas pelas páginas web incluídas no estudo. Esse número se aplica a cada página web/unidade de análise e pode ser somado em todas as páginas do conjunto analisado e dividido pelo número total de páginas web/unidades de análise $(n=607)$ a fim de gerar uma média de desempenho dos portais web analisados em cada região geográfica e em todo o país, sendo denominado Índice de Qualidade da Informação (IQI).

Coleta e análise de dados para classificação nas categorias de análise foram realizadas por meio da aplicação de planilhas eletrônicas, com o suporte de quatro estudantes de graduação em comunicação da Universidade Estadual Paulista (Unesp), das quais três receberam bolsas do Programa Institucional de Bolsas de Iniciação Científica (Pibic), do Conselho Nacional de Desenvolvimento Científico e Tecnológico (CNPq), e uma recebeu bolsa de Treinamento Técnico da Fapesp³ ${ }^{3}$ Cada planilha referente a uma unidade federativa foi preenchida por uma bolsista e revisada por outra bolsista. Nos casos de eventual discordância entre as bolsistas sobre a classificação inicial, a decisão final de classificação foi avaliada por uma terceira bolsista, sob a supervisão do pesquisador responsável, que eventualmente procedeu a ajustes em busca de confiabilidade entre os codificadores, que, no entanto, não teve seu índice específico calculado, em função dos limites do desenho de pesquisa.

3 Agradecemos às bolsistas Pibic/CNPq e Fapesp/TT1. 


\section{RESULTADOS E DISCUSSÃO}

A análise de 607 páginas web de organizações governamentais ambientais ou equivalentes das 27 unidades federativas ou órgãos equivalentes, acessadas nos anos de 2016 e 2017, indicou a existência de desempenho variável do Índice de Qualidade da Informação (IQI) entre aproximadamente 14,8\% e 28,7\% do total que seria necessário, no contexto teóricometodológico da pesquisa, para a caracterização completa de uma política de sustentabilidade ambiental. A média encontrada do IQI foi de 21,2\%, o que significa que o censo de páginas web analisadas apresenta pouco mais de um quinto das informações relevantes necessárias.

Na interpretação dos resultados, os 26 estados brasileiros e o Distrito Federal foram agrupados nas cinco macrorregiões existentes, uma divisão política ainda justificada em função da ocorrência de patamares similares de desenvolvimento econômico e social, que considera os estados abrangidos para finalidade de desenho e implementação de políticas públicas integradas territorialmente, em áreas diversas.

Gráfico 1: Percentuais de informação observados nos portais web de organizações governamentais ambientais das 27 unidades federativas brasileiras, agrupadas por macrorregião geográfica

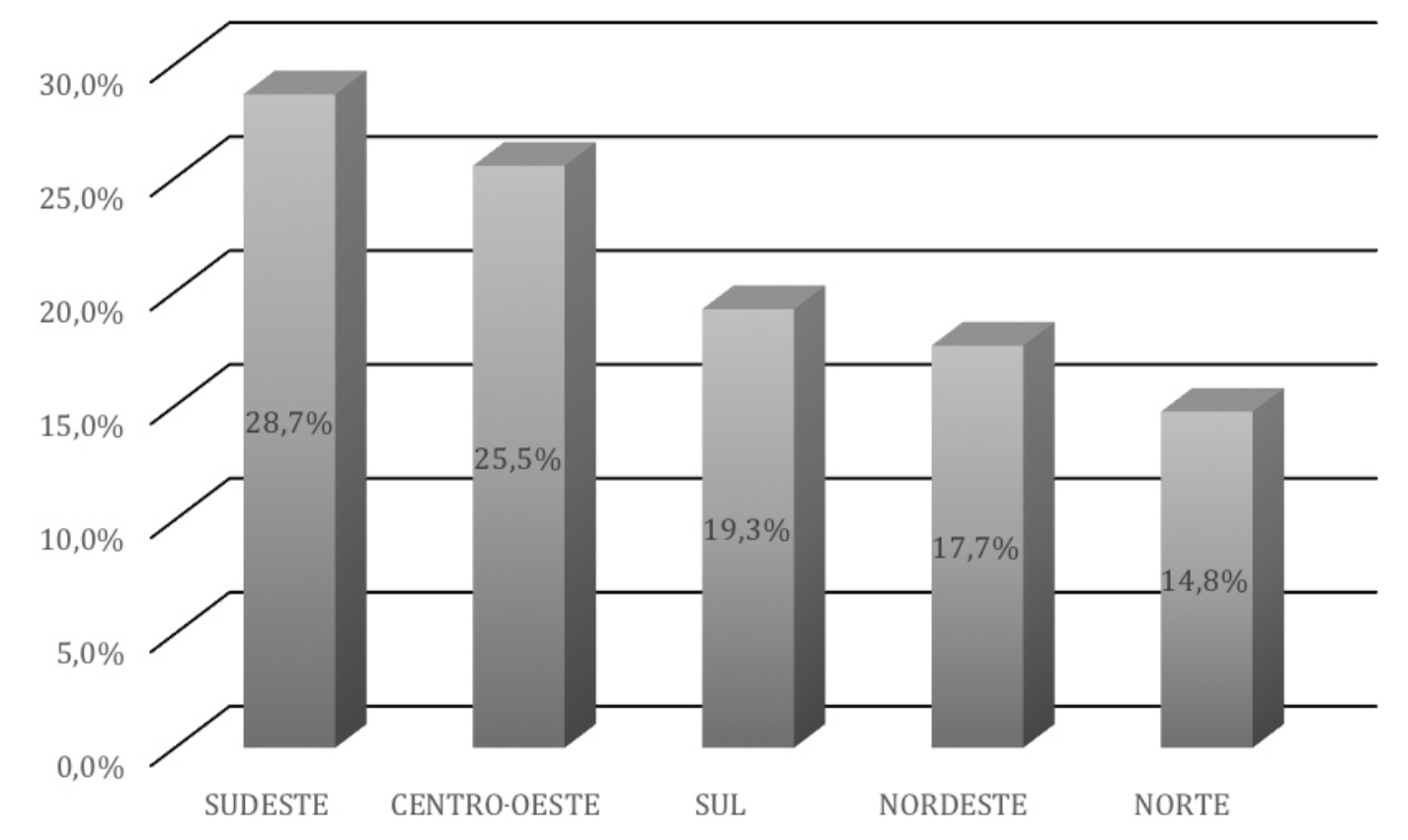

Fonte: Elaborado pelo autor.

De acordo com o Gráficol, as páginas web das organizações governamentais ambientais dos estados da região Sudeste apresentaram melhor desempenho na transparência ativa, exibindo 28,7\% das informações consideradas necessárias segundo o contexto teórico-metodológico da pesquisa, seguidas por Centro-Oeste (25,5\%), Sul (19,3\%), Nordeste (17,7\%) e Norte (14,8\%).

0 Gráfico2 indica as categorias de informação nas quais estiveram concentrados os dados encontrados nos portais web de governo selecionados para análise. 


\section{ANO 16 • NÚMERO 31 • 2 SEM. 2019 • ORGANICOM \\ TRANSPARÊNCIA ATIVA EM ORGANIZAÇÕES GOVERNAMENTAIS DE \\ SUSTENTABILIDADE AMBIENTAL}

Gráfico 2: Percentuais de informações sobre políticas públicas por categorias de análise de conteúdo encontradas em portais web de organizações governamentais ambientais das 27 unidades federativas brasileiras

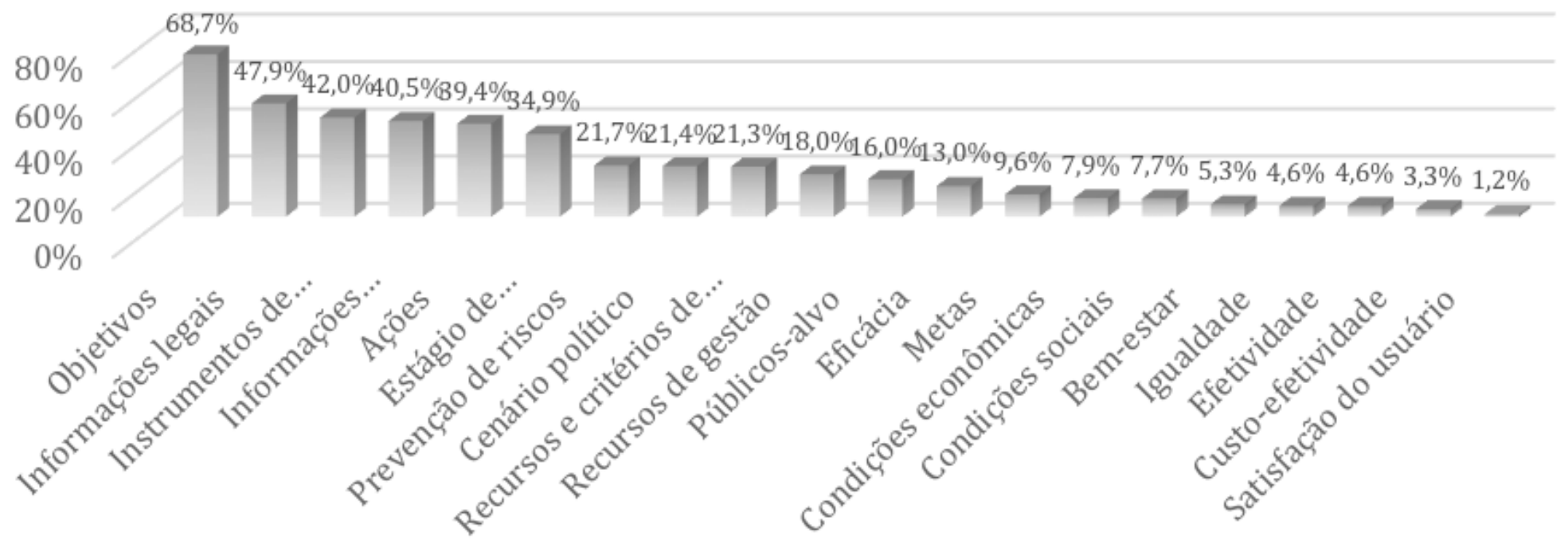

Fonte: Elaborado pelo autor.

Os dados exibidos no Gráfico 2 indicam que as informações mais encontradas se relacionaram à categoria "objetivos" (68,7\% das 607 páginas web apresentaram informações relacionadas), o que sugere a predominância de preocupações, entre os assessores de comunicação pública, com dados restritos à divulgação dos propósitos imediatos de uma política pública de sustentabilidade.

Para além da predominância de "objetivos", as categorias podem ser agrupadas em três faixas de desempenho. A primeira faixa vai de "informações legais" (47,9\% das páginas web analisadas apresentaram informações relacionadas) a "ações" $(39,4 \%)$, o que indica que os dados ainda abrangeram, embora em menor alcance, a legislação sustentando as políticas, meios de acessá-las, meios de contato com os gestores e as próprias realizações em si mesmas, de forma resumida. $A$ segunda faixa de desempenho abrange de "estágio de desenvolvimento científico e tecnológico" (34,9\%) a "eficácia" (13\%), sugerindo que foi de interesse minoritário entre os assessores de comunicação pública o foco sobre aspectos essenciais das políticas públicas de sustentabilidade, como prevenção de riscos, recursos de gestão e métodos de busca de eficácia, ou seja, de transformação efetiva das condições iniciais enfrentadas. A terceira faixa de desempenho, que vai de "metas" (9,6\%) a "satisfação do usuário" (1,2\%), abrange oito categorias de análise, das vinte do total considerado, que tiveram informações relacionadas presentes em menos de um décimo do censo analisado, sugerindo a notável escassez de dados fundamentais para a avaliação de uma política da área.

Tomados em conjunto o IQI médio de 21,2\%, apurado entre as 607 páginas web analisadas provenientes de portais web de governo das 27 unidades federativas brasileiras, e a escassez de informações em categorias importantes, os resultados sugerem a existência de oportunidades de aperfeiçoamento da comunicação pública para sustentabilidade no Brasil nas formas de transparência ativa, em conformidade com a legislação na área e de forma estratégica (Kunsch, 2018).

Por fim, podemos sugerir caminhos de busca de explicações das diferentes marcas de desempenho aferidas nos termos do IQI. 0 Gráfico3 sugere uma correlação entre desempenho na transparência ativa de portais web de organizações governamentais ambientais e Índice de Desenvolvimento Humano. 
Gráfico 3: Correlação entre desempenho na transparência ativa de portais web de organizações governamentais ambientais e Índice de Desenvolvimento Humano

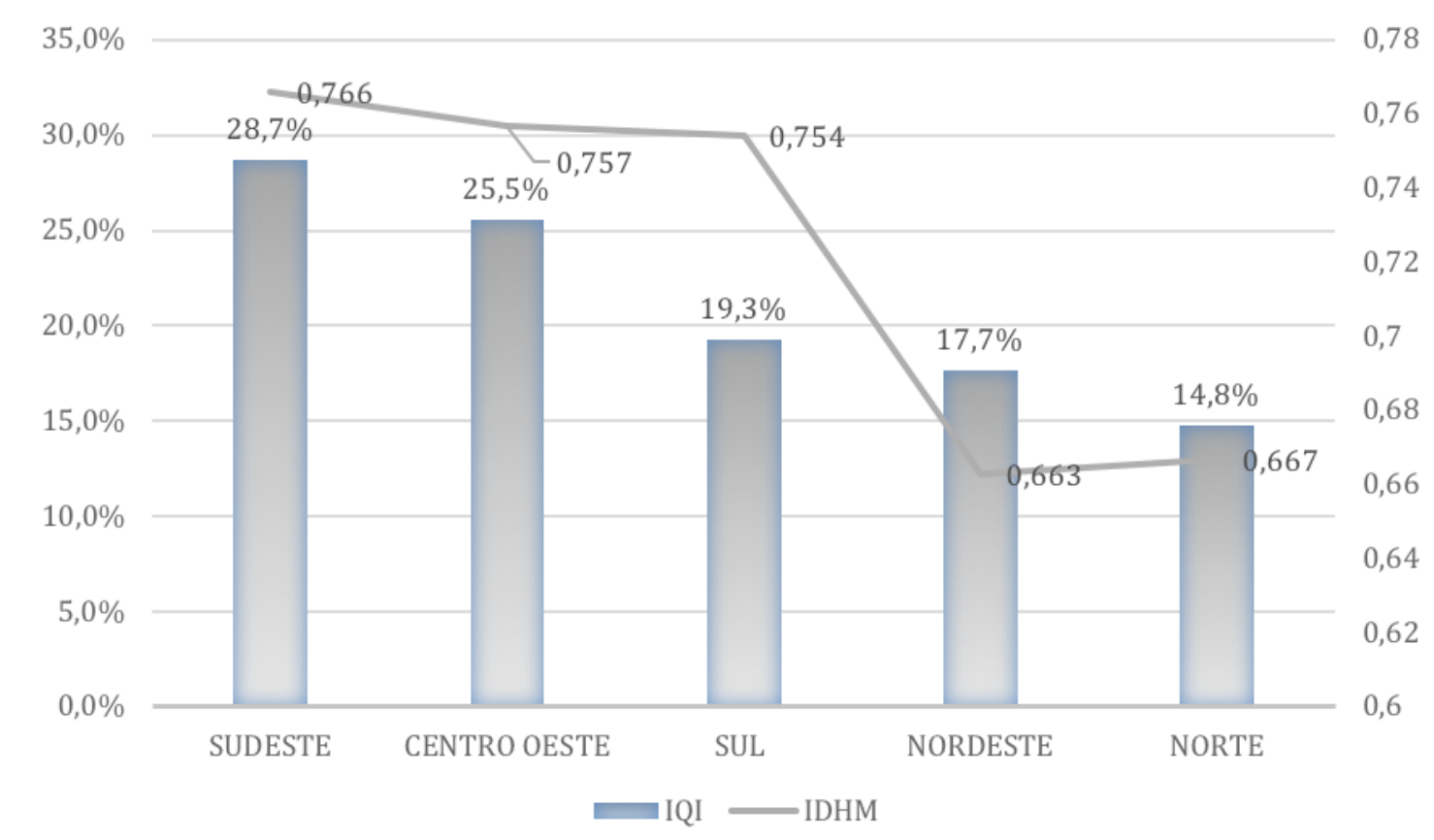

Fonte: Elaborado pelo autor, com dados de IDHM extraídos de PNUD (Ipea, 2016).

Nota-se, com base no Gráfico 3, uma associação positiva entre transparência ativa e desenvolvimento humano nas grandes regiões geográficas brasileiras, à medida que as regiões de melhor desempenho na comunicação pública estão à frente também nos indicadores de renda, educação e saúde apurados pelo Índice de Desenvolvimento Humano dos Municípios (IDHM) em 2016, ano de início da coleta de dados de nosso estudo (a curva não é linear, uma vez que Nordeste e Norte estão em posição ligeiramente invertida; no entanto, ambas estão em nível decrescente em relação às demais).

A construção de um desenho metodológico diferenciado, que esteve além dos limites de nossa pesquisa, seria requisito para apurar tal associação com acurácia e explicar com segurança por quais razões as regiões com melhores indicadores de renda, educação e saúde também apresentam melhor desempenho em comunicação pública e transparência ativa de políticas públicas de sustentabilidade. 0 que a literatura aqui mobilizada permite sugerir é que regiões com melhor desenvolvimento econômico e social tendem a ser habitadas por camadas de cidadãos mais dispostos a pressionar os governos pela oferta de informação pública e mais equipados para utilizar as informações em seu proveito, tanto para se orientar no cotidiano em relação a políticas que incluem destinação de resíduos, saneamento básico, tratamento e distribuição de água, objetos dos dados aqui analisados, quanto para se posicionar nos pleitos eleitorais (Darbishire, 2010; Meijer; Hart; Worthy, 2018). Em resposta, as assessorias de comunicação responderiam ao que pressentem ser uma demanda da sociedade e se engajariam na busca por elevada performance. Neste sentido, o dado que encontramos corrobora a evidência internacional.

No entanto, a literatura também fundamentaria a ressalva de que mesmo os IDHM mais altos no Brasil são inferiores às médias dos países da Organização para a Cooperação e Desenvolvimento Econômico (OCDE), o que indicaria a existência, no país, de adversidades capazes de alavancar capital social e motivar engajamento cívico - fatores de pressão sobre governos e vetores de benefícios oriundos do uso da informação pública (OCDE, 2018). Isto reforça a necessidade do avanço de um programa de pesquisa em comunicação nas organizações governamentais, ainda pouco explorada no Brasil. 


\section{CONSIDERAÇÕES FINAIS}

Nossa pesquisa apurou indicadores da qualidade da comunicação pública de organizações governamentais ambientais no contexto das exigências legais de transparência ativa. Os resultados indicam que a informação sobre políticas públicas de sustentabilidade ambiental existente em 607 páginas web de governo atendem a pouco mais de um quinto do que seria necessário, conforme o contexto teórico-metodológico adotado, para a caracterização abrangente de uma política da área. Os resultados sugerem também uma associação positiva entre desempenho da comunicação e desenvolvimento social e econômico, a ser explorada em estudos futuros.

Entre os limites do desenho de pesquisa, que podem ser superados por outras direções, esteve o foco restrito à transparência ativa, que ocorre independentemente de solicitações específicas. Este foco levou a não observação das práticas e rotinas da reação institucional aos pedidos de informação pela sociedade. As leis de acesso à informação tendem a gerar um impacto predominante na forma da transparência reativa, regrada por dispositivos legais para o recebimento de solicitações de dados pelos órgãos públicos, formulados por qualquer cidadão, e as obrigações legais para respondê-las. 0 desempenho dos assessores no processamento dessas solicitações é também influenciado por fatores que incluem aqueles examinados aqui a respeito de seu impacto sobre a transparência ativa, mas o desenho de nosso estudo não abrangeu a verificação desse aspecto, que merece pesquisas adicionais.

\section{REFERÊNCIAS}

BENJAMIN, Katherine; POTTS, Henry W. W. Digital transformation in government: lessons for digital health? Digital Health, Thousand Oaks, v.3, p.1-5, 2018.

BRASIL. Lei no 12.527, de 18 de novembro de 2011. Regula o acesso a informações previsto no incisoXXXIII do art. $5^{\circ}$, no inciso II do $\S 3^{\circ}$ do art. 37 e no $\S 2^{\circ}$ do art. 216 da Constituição Federal. Diário Oficial da União, Brasília,DF, p.1, 18 nov. 2011.

BRASIL. Decreto nำ7.724, de 16 de maio de 2012. Regulamenta a Lei no 12.527, de 18 de novembro de 2011 [...]. Diário Oficial da União, Brasília,DF, p.1, 16 maio 2012.

BRASIL. Manual de diretrizes: identidade padrão de comunicação digital do Poder Executivo federal. 34.ed. Brasília,DF: Secretaria de Comunicação Social, 2014.

COLEMAN, Stephen; BLUMLER, Jay G. The internet and democratic citizenship: theory, practice and policy. Cambridge: Cambridge University Press, 2009.

DAHLBERG, Lincoln. Re-constructing digital democracy: an outline of four "positions". New Media \& Society, Thousand Oaks, v.13, n.6, p.855-872, 2011.

DARBISHIRE, Helen. Proactive transparency, the future of the right to information? Washington,DC: World Bank Institute, 2010.

DOKENIYA, Anupama. Implementing right to information. Governance \& Public Sector Management, Washington,DC, n.5, p.1-8, 2013. 
DUARTE, Jorge. Sobre a emergência do(s) conceito(s) de comunicação pública. In: KUNSCH, Margarida Maria K. (org.). Comunicação pública, sociedade e cidadania. São Caetano do Sul: Difusão, 2011. p.121-134.

FONSECA JUNIOR, Wilson C. Análise de conteúdo. In: BARROS, Antonio; DUARTE, José (org.). Métodos e técnicas de pesquisa em comunicação. São Paulo: Atlas, 2006. p.280-304.

IPEA - INSTITUTO DE PESQUISA ECONÔMICA APLICADA. Desenvolvimento humano nas macrorregiões brasileiras. Brasília,DF: Ipea, 2016. Disponível em: http://www.ipea.gov.br/portal/images/stories/PDFs/livros/livros/20160331_livro-idhm.pdf. Acesso em: 29 out. 2018.

KRIPPENDORFF, Klaus. Content analysis: an introduction to its methodology. Beverly Hills: Sage, 1980.

KUNSCH, Margarida Maria K. A comunicação estratégica nas organizações contemporâneas. Media e Jornalismo, Lisboa, v.18, n.33, p.13-24, 2018.

MATOS, Heloiza. A comunicação pública na perspectiva da teoria do reconhecimento. In: KUNSCH, Margarida Maria K. (org.). Comunicação pública, sociedade e cidadania. São Caetano do Sul: Difusão, 2011. p. 39-59.

MEIJER, Albert; HART, Paul; WORTHY, Benjamin. Assessing government transparency: an interpretive framework. Administration \& Society, Thousand Oaks, v.50, n.4, p.501-526, 2018.

MIOLA, Edna; MARQUES, Francisco Paulo J. Por uma definição de comunicação pública: tipologias e experiências brasileiras. In: CONGRESSO DA ASSOCIAÇÃO BRASILEIRA DE PESQUISADORES EM COMUNICAÇÃO E POLÍTICA, 7., 2017, Porto Alegre. Anais [...]. Rio de Janeiro: Compolítica, 2017. p.1-22.

OAS-ORGANIZATION OF AMERICAN STATES. Model inter-American law on access to public information and its implementation guidelines. Washington,DC: Organization of American States, 2012.

OCDE. Better Life Index. [S.l.], 2018. Disponível em: http://www.oecdbetterlifeindex.org/pt. Acesso em: 21 jan. 2018.

ONU. Framework Convention on Climate Change: Paris Agreement. Paris: ONU, 2015.

ONU - ORGANIZAÇÃO NAS NAÇÕES UNIDAS. Framework Convention on Climate Change: Report of the Conference of the Parties. Paris: ONU, 2017.

ROTHBERG, Danilo. Democracia digital e redes sociais: Twitter como filtro de informação política. E-Compós, Brasília,DF, v.17, n.1, p.1-16, 2014.

ROTHBERG, Danilo. Teoria e pesquisa da comunicação digital para sustentabilidade. In: LIMA, M. C.; ALMEIDA JÚNIOR, Antônio; ANDRADE, T. N. (org.). Comunicação, tecnologia e ambiente. Recife: Hucitec, 2015. p.125-143.

ROTHBERG, Danilo. Acesso à informação, política digital e sustentabilidade ambiental no Brasil. Famecos, Porto Alegre, v.25, n.3, p.1-19, 2018. 
WEBER, Maria H. Nas redes de comunicação pública, as disputas possíveis de poder e visibilidade. In: WEBER, Maria H.; COELHO, Maria P.; LOCATELLI, Carlos (org.). Comunicação pública e política: pesquisas e práticas. Florianópolis: Insular, 2017. p.23-56.

ZÉMOR, Pierre. As formas de comunicação pública. In: DUARTE, Jorge (org.). Comunicação pública: Estado, mercado, sociedade e interesse público. São Paulo: Atlas, 2009. p.214-245.

Texto recebido em 29.07.2019 e aprovado em 30.11.2019. 